\title{
PREFÁCIO
}

\section{PANDEMIA, DIREITO E FRATERNIDADE: UM MUNDO NOVO NASCERÁ}

A proliferação do novo Coronavírus, identificada pela Organização Mundial da Saúde (OMS) como uma pandemia, na medida em que se alastrou em progressão geométrica e global, convida o mundo à reinvenção e ao experimentalismo institucional. Às sociedades é exigido o redimensionamento de prioridades, de estilo de vida, das relações familiares, sociais e profissionais. Aos entes estatais, por sua vez, é imposto guiar e amparar essas mudanças, para que gerem o mínimo impacto socioeconômico possível.

É preciso lembrar que a humanidade já não se encontrava numa situação minimamente satisfatória antes da pandemia. Como exemplo, temos crises humanitárias, como os deslocamentos populacionais forçados, as guerras civis, os conflitos étnicos, a dizimação de etnias indígenas, as imigrações derivadas de regimes autoritários, as perseguições xenófobas, os refugiados, a exclusão social da periferia global, os genocídios e os conflitos militares.

Espera-se de todos (cidadãos, sociedade, governos e entes não-governamentais) o necessário movimento de ampliar e fortalecer os sistemas de saúde, bem como a implementação de outras medidas que possam minorar os picos de contágio (como isolamentos sociais e quarentenas) e as consequências sócio-econômicas daí decorrentes, reduzindo-se a desvantagem na corrida científica por possíveis curas e/ou vacinas.

De outra parte, são necessárias medidas de impactos imediatos na economia, altamente atingida pela Covid-19, tanto no que tange à empregabilidade quanto à renda de trabalhadores autônomos, notadamente em setores como construção civil, economia criativa (eventos e produções) e turismo.

A pandemia é, portanto, por definição, um problema global, que provoca uma dimensão que extrapola as fronteiras - transterritorialidade. A omissão ou qualquer ação irresponsável de um Estado traz consequência para os demais. Necessitamos construir pontes e não fortalezas!

Com efeito, em situação de emergência pública, os direitos fundamentais e humanos não podem ser suspensos. Eventual limitação deve ser sempre feita por lei e há de ser temporária, proporcional, estritamente razoável e necessária. Não pode ser também discriminatória ou tornar mais agudas as consequências já nefastas de exclusão social de segmentos da população, especialmente os mais carentes. 
O quadro passa a ser trágico e é indiscutivelmente complexa a estruturação de políticas públicas em curtíssimo espaço de tempo, com recursos financeiros reduzidos, diante de variáveis desconhecidas e imprevisíveis, e, notadamente, quando toda medida (omissiva ou comissiva) tem graves reflexos sociais - e inexiste um balanço de proteção excelente.

Um dos poucos aspectos tratados de forma veemente e uníssona nos discursos dos organismos internacionais e das sociedades civis é a necessidade de os países e cidadãos agirem rápido e coordenadamente, em busca do resgate da pedagogia da fraternidade, que promove as chamadas ações afirmativas ou políticas públicas afirmativas de integração civil e moral de segmentos historicamente discriminados, como o segmento das mulheres, dos deficientes físicos, dos idosos, dos negros, dos presidiários e assim avante.

Nesse contexto, o mínimo que se espera de um "pensamento de possibilidades" é alternativa do resgaste ao princípio da fraternidade, por ser esta "a categoria de pensamento capaz de conjugar a unidade e a distinção a que anseia a humanidade contemporânea"1. Isso porque a experiência e metodologia concernentes à fraternidade, tal como proposta por Chiara Lubich, são caracterizadas pelos seguintes elementos: (i) compreensão da fraternidade como experiência possível, (ii) o estudo e a interpretação da história à luz da fraternidade, (iii) a colaboração entre teoria e prática da fraternidade na esfera pública, (iv) a interdisciplinaridade dos estudos e (v) o diálogo entre culturas. ${ }^{2}$

Com essa diretriz metodológica, torna-se possível tratar a fraternidade como categoria política com aptidão a refundar a prática democrática, ao compatibilizar o relacionamento entre a igualdade (paridade) e a liberdade (diferença), em prol de uma causa unificante. Logo, o conteúdo mínimo desse princípio político expressa-se como a condição de igualdade entre irmãos e irmãs de modo a ser possível que cada um seja livre na sua própria diversidade. ${ }^{3}$

Sendo assim, a fraternidade abre-se a possibilidades atuais e futuras, ganhando universalidade perante a humanidade e a própria condição humana. Enfim, esse princípio político tem o potencial de atuar como método e conteúdo da política, ao tornar-se parte constitutiva do processo de tomada de decisões políticas, assim como guia hermenêutico das demais normas em interação dinâmica, inclusive em ambiente jurisdicional.

\footnotetext{
${ }^{1}$ LUBICH, Chiara. Mensagem ao I Congresso Nacional sobre o tema "Direito e Fraternidade. (Mariápolis Ginetta 25 a 27 jan. de 2008) Disponível em: http://groups.google.com/group/comunhao-e-direito/files?hl=pt-BR. Acesso em 8 dez 2008.

${ }^{2}$ BAGgiO, Antonio Maria. The Forgotten Principle: Fraternity in Its Public Dimension. Claritas - Journal of Dialogue and Culture, West Lafayette-EUA, v. 2, n. 2, pp. 35-58, 2013, p. 44.

${ }^{3}$ Ibid., p. 47.
} 
Por outro lado, dado que é valor jurídico-político próprio do constitucionalismo, também possui conteúdo no âmbito do Direito cuja estruturação emana da dignidade da pessoa humana. Ao traduzir-se no código jurídico, a fraternidade possui natureza normativa principiológica, servindo para a construção hermenêutica de outras normas, mas impondo comandos deônticos mediante a soberania estatal.

A respeito disso, recorre-se ao escólio de Clara Cardoso Machado Jaborandy:

Defende-se, portanto, que fraternidade é princípio fundamental introduzido de maneira expressa ou implícita no texto constitucional que atua como vetor interpretativo na construção de significado de outros enunciados, além de fomentar no indivíduo o reconhecimento da dignidade humana e realizar o princípio da responsabilidade no âmbito estatal, individual e coletivo.

Além disso, o princípio da fraternidade é fonte direta de direitos e deveres transindividuais na medida em que constitui fundamento jurídico-normativo de tais direitos. Assim, direitos fundamentais transindividuais que não estejam expressamente enumerados na Constituição serão protegidos em razão da fraternidade (...) $\mathrm{O}$ conteúdo da fraternidade realiza-se quando cada um, desempenhando sua função social, reconhece a existência e dignidade do outro, e é tratado pela sociedade individualmente com necessidades e fins próprios de forma que a felicidade, que é um fim individual por excelência, se realize em comunidade. ${ }^{4}$

Por conseguinte, considerada a Constituição como o estatuto jurídico do político, a fraternidade possui guarida como princípio explícito ou implícito na Constituição da República de 1988, como bem destaca Carlos Augusto Alcântara Machado:

A Constituição do Brasil de 1998, já no preâmbulo, assume tal compromisso, ao referir-se, de forma expressa, que perseguirá, com a garantia de determinados valores, a sociedade fraterna. Adiante, indica como objetivo fundamental, além dos tradicionais e clássicos misteres estatais com a liberdade e a igualdade, a construção de uma sociedade solidária (art. $3^{\circ}, \mathrm{I}-\mathrm{CF}$ ).

Ademais, o sistema jurídico constitucional brasileiro, além de garantir direitos de status diferenciado, como destacado, busca assegurar o bem-estar de todos os que se submetem à ordem jurídica pelo constituinte plasmado por meio e a partir da Constituição de 1988. Assim, em oito oportunidades, considerando a dimensão fraternal do constitucionalismo, refere-se ao bem-estar, inicialmente como valor supremo de uma sociedade fraterna, no preâmbulo da Constituição Federal, e depois em campos específicos do seu disciplinamento normativo: no art. 23, parágrafo único (bem-estar nacional); no art. 182, caput (bem-estar dos habitantes da cidade); art. 186, IV (bem estar dos proprietários e trabalhadores - requisito para aferição da função social da propriedade rural); art. 193, caput (bem-estar social); art. 219, caput (bemestar da população); art. 230, caput (bem-estar dos idosos) e art. 231, §1 ${ }^{\circ}$ (bem-estar dos índios). 5

A presente Obra coletiva justifica-se, portanto, não só pela questão altercada referente às ações afirmativas em sociedades democráticas e Estados constitucionais, mas igualmente pela engenhosa prática de vida dos autores, que dá prova permanente de seu compromisso, coerência e coragem com os direitos fundamentais de fraternidade.

\footnotetext{
4 JABORANDY, Clara Cardoso Machado. A Fraternidade no Direito Constitucional Brasileiro: um instrumento para proteção de direitos fundamentais transindividuais. Tese (Doutorado) - Universidade Federal da Bahia, Salvador, 2016, p. 71.

${ }_{5}^{5}$ MACHADO, Carlos Augusto Alcântara. A Garantia Constitucional da Fraternidade: constitucionalismo fraternal. 272 f. Tese (Doutorado) - Pontifícia Universidade Católica de São Paulo, São Paulo, 2014, p. 130.
} 
Estão de parabéns, pois, seus organizadores Josiane Rose Petry Veronese, Carlos Augusto Alcântara Machado e Lafayette Pozzoli, Professores Doutores de renomadas universidades brasileiras, que conseguiram reunir artigos e autores, que representam o que há de melhor no mundo da Academia.

Os artigos selecionados revelam a engenhosidade da solução fraterna adotada, tal como nos é apresentada, na doutrina, a "teoria do pensamento das possibilidades", de Peter Häberle, ultrapassando formalismos expostos como igualdade formal e liberdades na diferença sem pretensões de união. Nesse quadro, somente a fraternidade como categoria do pensamento possui condições de relacionar harmonicamente as demandas de paridade e distinção, especialmente, em tempos de pandemia, a fim de fortalecer a democracia brasileira e concretizar os direitos fundamentais de minorias sociais.

Os artigos que compõem esta Obra evidenciam a secularização e incorporação da fraternidade na retórica moderna, ao possibilitar sua existência na esfera pública como critério ético de tomada de decisão coletiva.

Articula-se, ainda, o resgaste do princípio da fraternidade em momento pós-secular, ante a crise existencial do Estado-nação. Assim, como elo entre a igualdade e a liberdade, o terceiro elemento da tríade da Revolução Francesa adquire nova função política voltada a refundar a prática democrática no bojo do relacionamento entre a igualdade (paridade) e a liberdade (diferença), em prol de uma causa unificante com base na universalidade da condição humana.

No subsistema jurídico, a fraternidade também é recepcionada como vetor interpretativo e norma de matiz eminentemente principiológica, com assento constitucional expresso e implícito, com fulcro no princípio da dignidade da pessoa humana, fundamento de legitimidade da comunidade estatal.

Em suma:

a) a fraternidade tem condições de gerar uma contribuição específica à vida política institucional e ordinária, porquanto sua origem remonta a uma ligação universal entre seres igualmente dignos que tem por resultado um complexo sistema de solidariedade social e atenção aos necessitados, à luz da imperatividade de afirmação da ética pública. Na condição de categoria política, o ideal fraternal promete refundar a prática democrática, ao compatibilizar o relacionamento entre a igualdade (paridade) e a liberdade (diferença), em prol de uma causa única. Em termos políticos, o conteúdo desse princípio expressa-se pela condição de igualdade entre irmãos e irmãs que sirva de suporte ao desenvolvimento livre de cada qual na sua própria diversidade. Portanto, na forma de parte constitutiva do processo de tomada de decisões públicas e guia hermenêutico das demais normas em interação dinâmica, a fraternidade consiste 
em método e teor da política. ${ }^{6}$

b) no bojo do universo jurídico, a fraternidade também é parâmetro normativo de correção da conduta de sujeitos de direito, ou seja, consiste em categoria jurídica relacional com aptidão para regular a vida gregária e estabilizar as expectativas sociais no tocante às condutas humanas. Ante essa razão, o ideal fraternal assume centralidade nas operações de fundamentação, legitimação, identificação, qualificação e positivação de direitos fundamentais.

Nessa linha de raciocínio, precisamos de uma sociedade que evite as discriminações e promova as chamadas ações afirmativas ou políticas públicas afirmativas de integração civil e moral de segmentos historicamente discriminados, como o segmento das mulheres, dos deficientes fisicos, dos idosos, dos negros, e assim avante (STF, ADI 3.128-7/DF).

Há, pois, significativa utilidade em uma categoria normativa que indica vias comunicacionais para solução de controvérsias sociais e a gerência comum da vida pública, à luz de valores humanistas como tolerância, compaixão e irmandade.

Por fim, a partir das experiências de vida (aspectos da saúde, da educação, do meio ambiente, da família, da criança e do adolescente, dos índios, das mulheres, dos negros, dos trabalhadores, das empresas, da Justiça e das instituições), contadas pelos autores, engajados no fortalecimento de um constitucionalismo brasileiro democrático, lança-se o desafio segundo o qual o direito fraterno humanista detém aptidão para representar novo paradigma jurídico com poder explicativo e propositivo aos dilemas imprevisíveis do século XXI. Um mundo novo nascerá!

Boa leitura ao Leitor. Congratulações aos Autores.

Brasília, 10 de julho de 2020.

\section{Reynaldo Soares da Fonseca}

Ministro do Superior Tribunal de Justiça. Professor Adjunto de Direito da Universidade Federal do Maranhão. Pós-Doutor em Democracia e Direitos Humanos pela Universidade de Coimbra. Doutor em Direito Constitucional pela Faculdade Autônoma de São Paulo. Mestre em Direito Público pela Pontifícia Universidade Católica de São Paulo.

DOI: https://doi.org/10.47306/978-65-88213-03-2.8-12

\footnotetext{
${ }^{6}$ FONSECA, Reynaldo Soares da. O Princípio Constitucional da Fraternidade: seu resgate no sistema de Justiça. Belo Horizonte: D’Plácido, 2019, p. 55.
} 